\title{
Arm Pain Versus Neck Pain: A Novel Ratio as a Predictor of Post-Operative Clinical Outcomes in Cervical Radiculopathy Patients
}

\author{
PETER G. PASSIAS, MD, ${ }^{1}$ SAQIB HASAN, MD,${ }^{1}$ KRIS RADCLIFF, $M D,{ }^{2}$ ROBERT ISAACS, MD,${ }^{3}$ \\ KRISTINA BIANCO, BA, ${ }^{1}$ CYRUS M. JALAI, BA, ${ }^{1}$ GREGORY W. POORMAN, BA, ${ }^{1}$ NANCY J. WORLEY, \\ BA, ${ }^{1}$ SAMANTHA R. HORN, BA, ${ }^{1}$ ANTHONY BONIELLO, BA, ${ }^{1}$ PETER L. ZHOU, BA, ${ }^{1}$ PAUL M. ARNOLD, \\ MD ${ }^{4}$ PATRICK HSIEH, MD ${ }^{5}$ ALEXANDER R. VACCARO, MD ${ }^{2}$ MICHAEL C. GERLING, MD ${ }^{1}$ \\ ${ }^{1}$ Orthopaedic Surgery, NYU Hospital for Joint Diseases, New York, New York, ${ }^{2}$ Department of Orthopedic Surgery, Rothman Institute, Thomas Jefferson \\ University, Philadelphia, Pennsylvania, ${ }^{3}$ Division of Neurosurgery, Duke University, Durham, North Carolina, ${ }^{4}$ Neurosurgery, University of Kansas Hospital, \\ Kansas City, Kansas, ${ }^{5}$ Department of Neurological Surgery, Keck School of Medicine of USC, Los Angeles, California
}

\begin{abstract}
Background: Informed patient selection and counseling is key in improving surgical outcomes. Understanding the impact that certain baseline variables can have on postoperative outcomes is essential in optimizing treatment for certain symptoms, such as radiculopathy from cervical spine pathologies. The aim was to identify baseline characteristics that were related to improved or worsened postoperative outcomes for patients undergoing surgery for cervical spine radiculopathic pain.

Methods: Retrospective review of prospectively collected data. Patient Sample: Surgical cervical spine patients with a diagnosis classification of "degenerative." Diagnoses included in the "degenerative" category were those that caused radiculopathy: cervical disc herniation, cervical stenosis, and cervical spondylosis without myelopathy. Baseline variables considered as predictors were: (1) age, (2) body mass index (BMI), (3) gender, (4) history of cervical spine surgery, (5) baseline Neck Disability Index (NDI) score, (6) baseline SF-36 Physical Component Summary (PCS) scores, (7) baseline SF-36 Mental Component Summary (MCS) scores, (8) Visual Analog Scale (VAS) Arm score, and (9) VAS Neck. Outcome Measures: Improvement in NDI ( $\geq 50 \%)$, VAS Arm/Neck ( $\geq 50 \%)$, SF-36 PCS/MCS $(\geq 10 \%)$ scores at 2-years postoperative. An arm-to-neck ratio (ANR) was also generated from baseline VAS scores. Univariate and multivariate analyses evaluated predictors for 2-year postoperative outcome improvements, controlling for surgical complications and technique.

Results: Three hundred ninety-eight patients were included. Patients with ANR $\leq 1(\mathrm{n}=214)$ were less likely to reach improvements in 2-year NDI $(30.0 \%$ vs $39.2 \%, P=.050)$ and SF-36 PCS $(42.4 \%$ vs $53.5 \%, P=.025)$. Multivariate analysis for neck disability revealed higher baseline SF-36 PCS (odds ratio [OR] 1.053) and MCS (OR 1.028) were associated with over $50 \%$ improvements. Higher baseline NDI were reduced odds of postoperative neck pain improvement (OR 0.958). Arm pain greater than neck pain at baseline was associated with both increased odds of postoperative arm pain improvement (OR 1.707) and SF36 PCS improvement (OR 1.495).

Conclusions: This study identified specific symptom locations and health-related quality of life (HRQL) scores, which were associated with postoperative pain and disability improvement. In particular, baseline arm pain greater than neck pain was determined to have the greatest impact on whether patients met at least $50 \%$ improvement in their upper body pain score. These findings are important for clinicians to optimize patient outcomes through effective preoperative counseling.
\end{abstract}

Article

Keywords: arm neck ratio, radiculopathy, cervical spine, neck pain, arm pain

\section{INTRODUCTION}

Patients presenting with cervical radiculopathy often present with concomitant axial neck pain. ${ }^{1}$ Radiculopathy is characterized by a history marked by functional limitation and disability, with studies describing more than half of radiculopathic patients continuing to have a minor to moderate degree of morbidity at long-term follow-up. ${ }^{2}$ Studies have also described generally favorable outcomes in regards to surgical intervention for radiculopathy. ${ }^{3-6}$ Radiculopathy and axial neck pain are rarely mutually exclusive and highlight the broader spectrum of cervical degenerative disc degeneration, 
which Rothman classically described as a "a chronic disease, productive of significant pain and incapacity over an extended period of time."7

Traditionally, operative management has been suggested to be reserved for patients with predominantly radicular symptoms and localized neurological findings while patients with mainly axial pain are conversely managed nonoperatively. Success rates are high for surgical decompression for radiculopathy, with reports of $80 \%$ to $90 \%$ of patients experiencing relief in arm pain. ${ }^{3-6}$ With predominant axial neck pain complaints, however, outcomes have been less reliable, with satisfaction ranging from $60 \%$ to $80 \% .^{8-11}$ While the cervical spine literature has largely focused on factors such as age, smoking history, comorbidities, and psychosocial factors as predictors of surgical outcomes, there is a paucity of literature extending beyond these factors. Health-related quality of life (HRQL) measures is one such proposed predictive factor with recent interest in utilizing HRQLs not only for measuring improvement, but also serving as preoperative predictors of outcomes. ${ }^{12}$ Recent studies in the lumbar spine literature have shown a correlation between higher patient-reported numerical leg pain and better decompression surgery outcomes. ${ }^{13,14}$

The value and relationship of radicular arm pain to axial neck pain as a predictor of postoperative outcomes have yet to be elucidated. ${ }^{12,15-17}$ The purpose of this study was therefore to use a multiinstitutional database to quantify metrics for upper body pain and disability scores, and to determine whether baseline characteristics varied with pain location ratios. A secondary aim was to determine whether preoperative pain location ratios predicted surgical outcomes. Because clinical improvements in neck pain after cervical spine surgery is associated with improved patient satisfaction, consideration of relative arm pain and axial neck pain scores may assist in clinical decision-making and in establishing realistic patient expectations of surgery. ${ }^{18}$

\section{MATERIALS AND METHODS}

\section{Data Source}

This study was a retrospective review of the Prospective Spine Treatment Outcomes Study (PROSTOS) database. PROSTOS is a part of the Association for Collaborative Spinal Research (ACSR) and 2221 patients treated for spinal pathology collected at 14 nationwide surgical sites.
Institutional review board (IRB) approval was obtained from each contributing center prior to study initiation.

\section{Inclusion Criteria}

This study examined patients receiving surgical treatment for radiculopathic cervical spine complaints: cervical disc herniation, cervical stenosis, and cervical spondylosis without myelopathy. Patients without baseline and 2-year demographic and HRQL data were excluded.

\section{Predictor Variables}

We sought to examine outcomes according to predictor variables commonly used in clinical practice for cervical radiculopathy patients. Predictive variables selected included the following: age, body mass index (BMI), gender, history of previous cervical surgery, baseline neck disability index (NDI), baseline Short-Form 36 Physical Component Summary (PCS) score, and baseline ShortForm 36 Mental Component Summary (MCS) score, baseline visual analog scale (VAS), and arm pain greater than neck pain. NDI, VAS, and SF-36 questionnaires have been validated and used in spine surgery. We created a ratio of arm pain to neck pain (arm pain-neck pain ratio [ANR]) to compare the 2 values. Values greater than 1 indicated arm pain greater than neck pain. All other values, including equal findings, were considered otherwise. This measure, and much of the analysis, was adapted from Cook et al, ${ }^{19}$ which evaluated HRQL, pain, and disability outcomes in patients with leg pain greater than back pain after lumbar discectomy.

\section{Outcome Measures}

The NDI assesses neck pain and a higher score indicates more severe disability. A higher score on the VAS for neck and arm pain indicates worse pain. In the MCS and PCS, a lower score means more severe disability. The SF-36 MCS and PCS are created by finding the average of all of the emotionally or physically relevant questions of the questionnaire.

Change from baseline to 2-year VAS Arm, VAS Neck, NDI, SF-36 MCS, and SF-36 PCS was assessed by taking the difference, dividing by the baseline score, and multiplying by 100 . Use of percentage change is recommended in the Initiative 
on Methods, Measurement, and Pain Assessment in Clinical Trials (IMMPACT) group to establish clinically meaningful outcome constructs. ${ }^{20}$ Primary analysis utilized 4 different dichotomous, 2-year outcome measures: improvement in VAS Arm 50\%, VAS Neck $50 \%$, NDI $50 \%$, SF-36 PCS $10 \%$ improvement, and SF-36 MCS 10\% improvement. Percent changes were calculated from baseline to 2 years postoperative accordant to IMMPACT recommended pain and disability reduction threshold for success.

\section{Statistical Analyses}

Univariate analysis, including $\chi^{2}$ tests for categorical variables and $t$ tests on continuous variables, evaluated outcomes according to different predictor variables. Independent bivariate logistic regression models were then created to consider predictors from univariate analyses that yielded a $P$ value $<$ .05 for each of the dichotomous HRQL outcome measures. Control variables were used to control interactions within the modelling, isolating the effect of predictor variables. The presence or absence of complications, surgical approach utilized, and diagnosis were controlled. Presence of complications were assessed by identifying any form of complication during the time period studied. The effect of surgical approach (anterior, posterior, or anterior-posterior) on patient outcomes were controlled for utilizing these control variables. A $P$ value of $<.05$ was considered statistically significant for all analyses; odds ratios (ORs) are reported as (OR $[95 \%$ confidence interval (CI)], $P$ value). Statistical analyses were performed using Statistical Package for the Social Sciences version 20.0 (SPSS Inc, Chicago, Illinois).

\section{RESULTS}

\section{Patient Population}

Of the 2221 patients in the database with radiculopathy, 631 patients underwent procedures for cervical disc herniation, cervical stenosis, or cervical spondylosis without myelopathy. One hundred three patients were missing demographic or operative data. One hundred thirty patients were missing 2-year follow-up. Therefore, 398 surgical patients with degenerative cervical spine diagnoses related to radiculopathy with complete 2-year follow-up data were included for analysis. The descriptive statistics for the total patient cohort are presented in Table 1. On average, radiculopathy patients experienced symptoms 94 weeks (range: 6572 weeks) prior to surgical treatment. The overall patient population was on $52.1 \pm 10.5$ years old (range: 21-84 years), presented with an average BMI of $28.7 \pm 5.9 \mathrm{~kg} / \mathrm{m}^{2}$, and was $64.4 \%$ female. There were 55 patients $(8.6 \%)$ who reported a prior cervical surgery, the most frequent treatment at $\mathrm{C} 5$ C6 (58.2\%) and C6-C7 (52.7\%).

\section{Treatment Method}

Preoperatively, patients were predominantly treated with the following conservative modalities physical therapy $(33.3 \%)$, narcotics $(32.3 \%)$, or nonsteroidal anti-inflammatory drugs $(31.4 \%)$. Surgically, all patients underwent anterior cervical discectomy and fusion procedures, with some patients also undergoing a removal of the posterior longitudinal ligament. The most frequently operated levels were C5-C6 (39.7\%), C6-C7 (24.9\%), and C4C5 (20.0\%). Discectomies occurred most frequently anteriorly at the C5-C-6 level (54.3\%), and decompression with lamino-foraminotomies and/or laminectomies were most prevalent at C5 (3.7\%).

\section{HRQL Metrics Change at 2 Years}

For the NDI, patients who improved in neck pain from baseline to 2 years had an average improvement by $17.13 \pm 8.05$ and the average 2-year NDI score was $9.25 \pm 8.57$. The average 2-year VAS neck scores for patients who improved from baseline to 2 years was $1.71 \pm 1.36$ and $6.52 \pm$ 1.88 for patients who did not improve in VAS neck.

The average SF-36 PCS score at 2 years for patients who improved in this metric was $45.35 \pm$ 9.81, and the average for patients who did not improve was $32.01 \pm 10.38$. For the SF-36 MCS, the average 2-year score for those who improved was $46.41 \pm 11.69$ and $37.99 \pm 13.71$. Differences between improvement groups for every HRQL were statistically significant (all $P<.001$ ).

\section{Arm-to-Neck Pain Ratio}

Table 2 describes patients' improvement on NDI, SF-36 MCS, and SF-36 PCS in relation to their ANR. One hundred fifty-six patients $(42.2 \%)$ had arm greater than neck pain preoperatively. Patients whose ANR was less than 1 were less likely to have greater change in baseline 2-year NDI $(30.0 \%$ vs $39.2 \%, P=.050)$ and SF-36 PCS $(42.4 \%$ vs $53.5 \%$, 


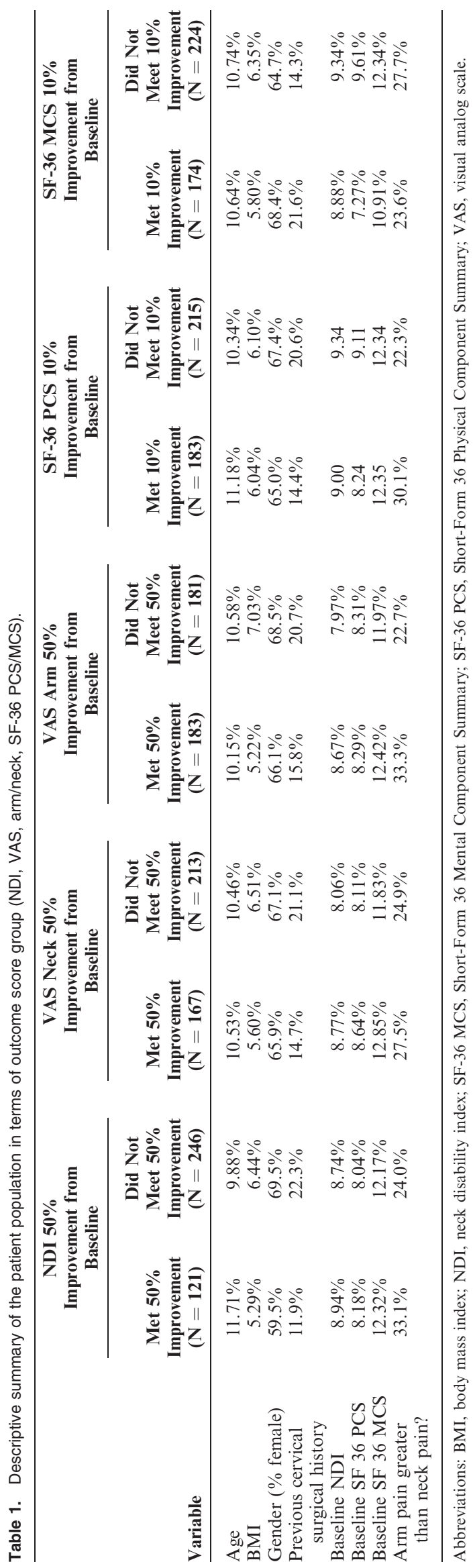

Table 2. Distribution of patients meeting 2-year NDI, SF-36 PCS/MCS improvement based on ANRs at baseline.

\begin{tabular}{lccc}
\hline & $\begin{array}{c}\text { Arm }<\text { Neck } \\
(\mathbf{n}=\mathbf{9 9})\end{array}$ & $\begin{array}{c}\text { Arm }>\text { Neck } \\
(\mathbf{n}=\mathbf{1 5 6})\end{array}$ & $\boldsymbol{P}^{\mathbf{a}}$ \\
\hline NDI 2-yr 50\% improvement & $30.0 \%$ & $39.2 \%$ & $\mathbf{. 0 5 0}$ \\
SF-36 PCS 2-yr 10\% improvement & $42.4 \%$ & $53.5 \%$ & $\mathbf{. 0 2 5}$ \\
SF-36 MCS 2-yr 10\% improvement & $46.9 \%$ & $37.0 \%$ & $\mathbf{. 0 4 1}$ \\
\hline
\end{tabular}

Abbreviations: ANR, arm-to-neck pain ratio; NDI, neck disability index; SF-36 MCS, Short-Form 36 Mental Component Summary; SF-36 PCS, Short-Form 36 Physical Component Summary.

${ }^{a}$ Difference between arm $\leq$ neck and arm $>$ neck. Bold indicates significant values.

$P=.025)$. These patients conversely were more likely to meet $10 \%$ SF-36 MCS improvement from baseline $(46.9 \%$ vs $37.0 \%, P=.041)$.

\section{Postoperative Disability}

$30.4 \%(n=121)$ of patients met at least $50 \%$ improvement in NDI score 2 years postoperative, while $61.8 \%(\mathrm{n}=246)$ did not. Table 3 displays differences between cervical radiculopathy patients who did and did not improve in NDI score. There were fewer females in the group that met $50 \%$ postoperative NDI improvement $(59.5 \%$ vs $69.5 \%$, $P=.037$ ), and fewer prior cervical spine surgeries $(11.9 \%$ vs $22.3 \%, P=.039)$. The improved NDI group presented with higher SF-36 PCS, MCS, and NDI scores at baseline compared to patients who did not improve in 2-year NDI score. At baseline, $50 \%$ NDI improvement patients also reported significantly elevated rates of greater arm pain than neck pain $(33.1 \%$ vs $24.0 \%, P=.044)$. Increased SF-36 PCS (1.053 [1.016-1.091], $P=.005)$ and SF36 MCS (1.028 [1.003-1.054], $P=.028)$ independently increased the likelihood of improving by $50 \%$ for NDI from baseline to 2 years (Table 5).

\section{Postoperative Neck and Arm Pain}

At 2-year follow up, 167 patients $(43.9 \%)$ reached at least $50 \%$ improvement in VAS Neck score from baseline, and $183(50.3 \%)$ reached at least $50 \%$ improvement in VAS Arm scores. Differences in considered variables are presented in Table 3 . Patients meeting 50\% VAS Neck improvement displayed better HRQL scores at baseline: NDI was lower $(22.62$ vs $28.96, P<.001)$, while PCS (36.50 vs 32.94, $P<.001)$ and MCS (41.54 vs 35.92, $P<.001)$ were higher. On multivariate analyses (Table 4) only a statistically elevated baseline NDI score decreased the OR of $50 \%$ VAS Neck improvement (0.958 [0.919-1.151], $P=.045)$. Patients who improved $50 \%$ in VAS Arm 2-year 
Passias et al.

Table 3. Univariate analyses for $50 \%$ improvements at 2-year post-operative for NDI, VAS Neck/Arm, and SF-36 PCS/MCS scores. ${ }^{a}$

\begin{tabular}{|c|c|c|c|c|c|}
\hline Variable & $\begin{array}{c}\text { NDI } \\
P \text { Value }\end{array}$ & $\begin{array}{c}\text { VAS Neck } \\
P \text { Value }\end{array}$ & $\begin{array}{l}\text { VAS Arm } \\
P \text { Value }\end{array}$ & $\begin{array}{c}\text { SF-36 PCS } \\
P \text { Value }\end{array}$ & $\begin{array}{c}\text { SF-36 MCS } \\
P \text { Value }\end{array}$ \\
\hline Age & .940 & .434 & .756 & .782 & .108 \\
\hline BMI & .056 & .720 & .387 & .992 & .649 \\
\hline Gender & .037 & .440 & .354 & .344 & 255 \\
\hline Previous cervical surgical history & .039 & .144 & .236 & .146 & .100 \\
\hline Baseline NDI & $<.001$ & $<.001$ & & & $<.001$ \\
\hline Baseline SF 36 PCS & $<.001$ & $<.001$ & $<.001$ & .224 & .012 \\
\hline Baseline SF 36 MCS & .001 & $<.001$ & $<.001$ & $<.001$ & $<.001$ \\
\hline Arm pain greater than neck pain & .044 & .319 & .016 & .050 & .208 \\
\hline
\end{tabular}

Abbreviations: BMI, body mass index; NDI, neck disability index; SF-36 MCS, Short-Form 36 Mental Component Summary; SF-36 PCS, Short-Form 36 Physical Component Summary; VAS, visual analog scale.

${ }^{\mathrm{a}}$ Bold indicates significant values.

scores from baseline had better preoperative NDI scores $(23.25$ vs $27.63, P<.001)$, SF-36 PCS scores (36.25 vs 32.49, $P<0.001$ ), and SF-36 MCS scores (41.40 vs 34.82, $P<.001)$. Improved VAS Arm cohort also comprised a higher prevalence of patients reporting arm pain greater than neck pain at baseline $(33.3 \%$ vs $22.7 \%, P=.002)$. On multivariate analysis (Table 5) significant baseline factors that increased the odds of reaching $50 \%$ VAS Arm improvement at 2-year postoperative included the following: arm pain greater than neck pain (1.707 [1.073-2.716], $P=.024)$, SF-36 PCS score (1.046 [1.005-1.089], $P=.028)$, and SF-36 MCS score (1.038 [1.014-1.063], $P=.002)$.

\section{Postoperative Physical and Mental Outcomes}

One hundred eighty-three $(46.0 \%)$ patients met $10 \%$ SF-36 PCS baseline 2-year improvement, and $174(43.7 \%)$ did so for SF-36 MCS. The cohort that met $10 \%$ SF-36 PCS improvement had greater SF-36 MCS scores at baseline (42.26 vs $35.67, P<$ $.001)$, and had more patients who reported greater arm than neck pain preoperatively $(30.1 \%$ vs $22.3 \%, P=.050)$. Both baseline SF-36 MCS (1.044 [1.026-1.062], $P<.001)$ and arm greater than neck pain $(1.495[0.953-2.346], P=.024)$ were associated with greater odds of meeting $10 \%$ SF-36

Table 4. Multivariate analysis for $50 \%$ improvements at 2-year postoperative for NDI score. ${ }^{a}$

\begin{tabular}{lcc}
\hline Variable & Odds Ratio $(95 \%$ CI) & P Value \\
\hline Gender (\% female) & $0.899(0.495-1.631)$ & .725 \\
Previous cervical surgical history & $0.556(0.247-1.250)$ & .155 \\
Baseline NDI & $1.011(0.958-1.068)$ & .684 \\
Baseline SF-36 PCS & $1.053(1.016-1.091)$ & $\mathbf{. 0 0 5}$ \\
Baseline SF-36 MCS & $1.028(1.003-1.054)$ & $\mathbf{. 0 2 8}$ \\
Arm pain greater than neck pain & $1.319(0.683-2.546)$ & .410 \\
\hline
\end{tabular}

Abbreviations: NDI, neck disability index; SF-36 MCS, Short-Form 36 Mental Component Summary; SF-36 PCS, Short-Form 36 Physical Component

Summary.

${ }^{\mathrm{a} B}$ Bold indicates significant values. 2-year improvement. Patients who met 10\% SF-36 MCS 2-year improvement had better NDI (25.98 vs $23.74, P=.019)$, better SF-36 PCS (35.33 vs $36.07, P=.012)$ score at baseline, but worse SF-36 MCS (32.98 vs 43.14, $P<.001)$. Multivariate analysis showed that baseline SF-36 PCS (1.069 [1.016-1.125], $P=.010)$ increased the OR of SF-36 MCS improvement while preoperative SF-36 MCS (0.929 [0.899-0.959], $P<.001)$ decreased the OR (Table 6).

\section{DISCUSSION}

Spine surgery has historically been associated with more variability in indications and outcomes than other surgical procedures. ${ }^{21-23}$ Although the cause for this variability is multifactorial, accurately diagnosing a specific pain generator to select an appropriate treatment is difficult, yet necessary given surgical results for chronic benign pain syndromes without a reversible anatomic cause are generally poor. ${ }^{24-26}$ Given the ubiquitous nature of cervical degenerative disc disease in the adult population, the clinical presentation of cervical radiculopathy is varied with up to $80 \%$ of patients having concomitant neck pain associated with radicular pain and neurological symptoms. ${ }^{27}$ Multiple studies suggest that cervical discs and facet joints can generate pain with the prevalence rates ranging from $36 \%$ to $60 \% .^{25,28-30}$ Identification of factors that may help predict surgical outcomes has been a driving force in the spine literature since pain relief and improvements in functional disability have been shown to correlate to postoperative patient satisfaction in cervical spine surgery. ${ }^{9,18,31}$ In our study, we aimed to predict postoperative outcomes given preoperative arm and neck pain scores and to determine whether baseline characteristics varied with the ratio of those pain scores. 
Table 5. Multivariate analysis for $50 \%$ improvements at 2-year postoperative for VAS neck and arm scores. ${ }^{a}$

\begin{tabular}{lcccc}
\hline & \multicolumn{2}{c}{ VAS Neck } & & \multicolumn{1}{c}{ VAS Arm } \\
\cline { 2 - 4 } Variable & Odds Ratio (95\% CI) & $\boldsymbol{P}$ Value & Odds Ratio (95\% CI) & $\boldsymbol{P}$ Value \\
\hline Baseline NDI & $0.958(0.919-1.151)$ & $\mathbf{. 0 4 5}$ & $0.994(0.952-1.038)$ \\
Baseline SF 36 PCS & $1.020(0.981-1.060)$ & .323 & & $.7846(1.005-1.089)$ \\
Baseline SF 36 MCS & $1.021(0.998-1.044)$ & .079 & $1.038(1.014-1.063)$ & $\mathbf{. 0 2 8}$ \\
Arm pain greater than neck pain & NS & NS & $1.707(1.073-2.716)$ \\
\hline
\end{tabular}

Abbreviations: NDI, neck disability index; SF-36 MCS, Short-Form 36 Mental Component Summary; SF-36 PCS, Short-Form 36 Physical Component Summary; VAS, visual analog scale.

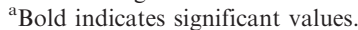

Traditionally, neck pain has been considered a poor prognostic indicator for surgical intervention. ${ }^{10,11}$ Williams et $\mathrm{al}^{11}$ reported on the outcomes of 99 patients following anterior cervical discectomy and fusion (ACDF) for cervical disc degeneration with less than 10-year follow-up and found that $73 \%$ of patients with radicular symptoms had good to excellent results compared to $26 \%$ with nonradicular symptoms. Similarly, DePalma and Rothman ${ }^{10}$ described approximately $70 \%$ of patients with chronic axial dominant neck pain, who were treated nonoperatively, had partial to no relief in their symptoms, while surgically treated patients had little functional benefit 5 years postoperatively. Other studies have highlighted the predominance of qualitative radicular symptoms in the context of superior outcomes. ${ }^{4,32-34}$ While these studies have shown that axial versus radicular pain symptoms may guide surgical treatment, none of these studies quantified region specific pain ratios as a prognostic value.

In contrast, early results of ACDF published by Smith and Robinson ${ }^{35}$ showed $73 \%$ good to excellent results for patients with predominant axial symptoms. However, interpretation of the authors' findings is limited by subjective, nonstandardized clinician evaluation of the subjects. ${ }^{35}$ More recent studies have shown surgical treatment for axial neck pain with minimal radicular complaints can have positive surgical outcomes with improvements in disability ranging from $32.3 \%$ to $51.9 \%$, improvement in patient reported pain ranging from $50 \%$ to
$60 \%$, and patient satisfaction ranging from $56 \%$ to $79 \% .{ }^{9,36,37}$ Nevertheless, interpretation of these results is limited given lack of level I to III evidence and absence of reporting of clinically meaningful improvement in pain and function. Our study utilized NDI, SF-36 MCS/PCS, and VAS scores for neck and arm as baseline measures of health status given their high level of reliability, validity, and responsiveness as outcome measures. ${ }^{38-40}$

Recent research into cervical surgical procedures for radiculopathy has focused on patient-reported outcome measures like the VAS as not only measurements of improvement, but also as preoperative predictors for surgical success. ${ }^{21-23}$ Via the use of established criteria for improvement for our outcome measures, ${ }^{19,41,42}$ our results show associations between ANR greater than or equal to 1 correlated with statistically significant improvements in NDI and SF-36 PCS 2 years after surgery. Baseline arm pain greater than neck pain similarly increased the odds of achieving improvement in SF36 PCS and VAS Arm scores following surgery. This is intuitive, given a patient with predominant radicular symptoms is more likely to have relief of the arm pain symptoms after adequate decompression of the affected nerve root.

The present study indicates that in patients with cervical radiculopathy due to degenerative disc disease, preoperative demographic and symptomatic factors may predict postoperative improvements in HRQL at 2-year follow-up. Furthermore, the

Table 6. Multivariate analysis for $50 \%$ improvements at 2-year postoperative for SF-36 PCS and MCS scores. ${ }^{\text {a }}$

\begin{tabular}{|c|c|c|c|c|}
\hline \multirow[b]{2}{*}{ Variable } & \multicolumn{2}{|c|}{ SF-36 PCS } & \multicolumn{2}{|c|}{ SF-36 MCS } \\
\hline & Odds Ratio (95\% CI) & $P$ Value & Odds Ratio (95\% CI) & $P$ Value \\
\hline Previous cervical surgical history & NS & NS & $0.642(0.290-1.420)$ & .274 \\
\hline Baseline NDI & NS & NS & $1.035(0.982-1.091)$ & .194 \\
\hline Baseline SF 36 PCS & NS & NS & $1.069(1.016-1.125)$ & .010 \\
\hline Baseline SF $36 \mathrm{MCS}$ & $1.044(1.026-1.062)$ & $<.001$ & $0.929(0.899-0.959)$ & $<.001$ \\
\hline Arm pain greater than neck pain & $1.495(1.053-2.346)$ & .024 & NS & NS \\
\hline
\end{tabular}

Abbreviations: NDI, neck disability index; SF-36 MCS, Short-Form 36 Mental Component Summary; SF-36 PCS, Short-Form 36 Physical Component Summary.

${ }^{a}$ Bold indicates significant values. 
present findings build on prior reports considering outcome scores in isolation by quantifying the ANR and utilizing this ratio as a predictor of outcomes in cervical spine surgery. By utilizing this novel ratio, we found that patients with higher neck than arm pain were less likely to improve in overall disability, physical and mental health postoperatively.

The present findings support the notion that patients with predominant axial neck symptoms are less likely to benefit from surgical intervention than those with predominant arm pain. Our findings are analogous to literature related to low back pain and leg pain in the context of lumbar spine surgery. Kleinstuck et $\mathrm{al}^{43}$ found that quantified low back pain and leg pain scores in patients presenting with spinal stenosis was the strongest predictor of 12 month outcomes. Similarly, using the Spine Patient Outcomes Research Trial (SPORT) data, Pearson et $\mathrm{al}^{41}$ found patients with degenerative spondylolisthesis and spinal stenosis who had predominant leg pain improved significantly more with surgery than patients with predominant back pain. Our results also show that a lower baseline NDI and higher SF36 PCS and MCS scores have an impact on improvements in postoperative neck and arm pain. This is consistent with published data, which has shown that patients with lower preoperative disability and pain have better outcomes. ${ }^{15,44}$

Limitations of this study include the retrospective nature, as well as the inherent flaws of large database studies such as coding errors and variable response rates. Additionally, conclusions in the group studied may not be generalizable to the population as a whole. Although we are utilizing accepted minimal clinically important differences (MCID) for our outcome measures, the use of VAS scores has not been shown to have the same reliability, validity, and responsiveness as the NDI and SF-36 measures. ${ }^{45}$ Additionally, our study is limited by 2-year follow-up, which may obscure clinically important changes that may occur in the immediate perioperative and short-term postoperative periods, as well as by current procedural terminology coding used for surgical procedures. This prospective cervical database was designed to study in an a priori manner predictors of the included patient derived outcomes; therefore, the performance of an actual ANR was not inherent to the design of the study. Radiographic variables were not included in the statistical model, hence, determination of successful fusion for ACDF surgeries was unable to be evaluated. Another limitation is that the ANR was developed by assessing the data retrospectively; however, we believe that a prospectively collected ANR would be a powerful surgical planning tool and should be incorporated into future prospective studies. In spite of these limitations, our study utilized a large number of patients with long-term follow-up.

\section{CONCLUSIONS}

Patient-reported outcome measures not only give quantitative data regarding general health quality, function, and pain, but also may predict long-term outcomes. Additionally, patient-reported arm-pain greater than neck-pain scores may predict positive long-term physical outcomes. This retrospective analysis of a spine registry data identified baseline factors that may be predictive of patient-reported outcomes subsequent to cervical spine surgery in patients with cervical radiculopathy, as well as analyzed the utility of a novel ratio, the ANR. By utilizing this novel ratio, the present study found that patients with higher neck than arm pain were less likely to improve in overall disability, physical and mental health postoperatively. While this may suggest a clinical utility for the use of the ANR, further studies are required to establish more evidence of these predictive measures.

\section{REFERENCES}

1. Roh JS, Teng AL, Yoo JU, Davis J, Furey C, Bohlman HH. Degenerative disorders of the lumbar and cervical spine. Orthop Clin North Am. 2005;36(3):255-262.

2. Lees F, Turner JW. Natural history and prognosis of cervical spondylosis. Br Med J. 1963;2(5373):1607-1610.

3. Bohlman HH, Emery SE, Goodfellow DB, Jones PK. Robinson anterior cervical discectomy and arthrodesis for cervical radiculopathy. Long-term follow-up of one hundred and twenty-two patients. $J$ Bone Joint Surg Am. 1993;75(9):1298-1307.

4. Gore DR, Sepic SB. Anterior cervical fusion for degenerated or protruded discs. A review of one hundred forty-six patients. Spine (Phila Pa 1976). 1984;9(7):667-671.

5. Simmons EH, Bhalla SK. Anterior cervical discectomy and fusion. A clinical and biomechanical study with eight-year follow-up. J Bone Joint Surg Br. 1969;51(2):225-237.

6. Smith GW, Robinson RA. The treatment of certain cervical-spine disorders by anterior removal of the intervertebral disc and interbody fusion. J Bone Jt Surg. 1958;40A(3):607-624.

7. Herkowitz HN, Garfin SR, Eismont FJ, Bell GR, Balderston RA. Rothman-Simeone The Spine: Expert Consult. Philadelphia: Elsevier Health Sciences; 2011.

8. Riley LH, Robinson RA, Johnson KA, Walker AE. The 
results of anterior interbody fusion of the cervical spine. Review of ninety-three consecutive cases. J Neurosurg. 1969;30(2):127133.

9. Palit M, Schofferman J, Goldthwaite N, et al. Anterior discectomy and fusion for the management of neck pain. Spine (Phila Pa 1976). 1999;24(21):2224-2228.

10. DePalma AF, Rothman RH, Lewinnek GE, Canale ST. Anterior interbody fusion for severe cervical disc degeneration. Surg Gynecol Obstet. 1972;134(5):755-758.

11. Williams JL, Allen MB, Harkess JW. Late results of cervical discectomy and interbody fusion: some factors influencing the results. J Bone Joint Surg Am. 1968;50(2):277-286.

12. Anderson PA, Subach BR, Riew KD. Predictors of outcome after anterior cervical discectomy and fusion: a multivariate analysis. Spine (Phila Pa 1976). 2009;34(2):161166.

13. Kleinstück FS, Grob D, Lattig F, et al. The influence of preoperative back pain on the outcome of lumbar decompression surgery. Spine (Phila Pa 1976). 2009;34(11):1198-1203.

14. Pearson A, Blood E, Lurie J, et al. Predominant leg pain is associated with better surgical outcomes in degenerative spondylolisthesis and spinal stenosis: results from the Spine Patient Outcomes Research Trial (SPORT). Spine (Phila Pa 1976). 2011;36(3):219-229.

15. Hermansen A, Hedlund R, Vavruch L, Peolsson A. Positive predictive factors and subgroup analysis of clinically relevant improvement after anterior cervical decompression and fusion for cervical disc disease: a 10- to 13-year follow-up of a prospective randomized study. $J$ Neurosurg Spine. 2013;19(4):403-411.

16. Frymoyer JW, Pope MH, Costanza MC, Rosen JC, Goggin JE, Wilder DG. Epidemiologic studies of low-back pain. Spine (Phila Pa 1976). 1980;5(5):4194-23.

17. Lawrence JTR, London N, Bohlman HH, Chin KR. Preoperative narcotic use as a predictor of clinical outcome: results following anterior cervical arthrodesis. Spine (Phila Pa 1976). 2008;33(19):2074-2078.

18. Skolasky RL, Albert TJ, Vaccaro AR, Riley LH. Patient satisfaction in the cervical spine research society outcomes study: relationship to improved clinical outcome. Spine J. 2009;9(3):232-239.

19. Cook CE, Arnold PM, Passias PG, Frempong-Boadu AK, Radcliff K, Isaacs R. Predictors of pain and disability outcomes in one thousand, one hundred and eight patients who underwent lumbar discectomy surgery. Int Orthop. 2015;39(11):2143-2151.

20. Dworkin RH, Turk DC, Wyrwich KW, et al. Interpreting the clinical importance of treatment outcomes in chronic pain clinical trials: IMMPACT recommendations. $J$ Pain. 2008;9(2):105-121.

21. Cherkin DC, Deyo RA, Loeser JD, et al. An international comparison of back surgery rates. Spine (Phila Pa 1976). 1994;19(11):1201-1216.

22. Deyo RA, Gray DT, Kreuter W, Mirza S, Martin BI. United States trends in lumbar fusion surgery for degenerative conditions. Spine (Phila Pa 1976). 2005;30(12):1441-1445.

23. Dunsker SB. Lumbar spine stabilization: indications. Clin Neurosurg. 1990;36:147-158.

24. Wetzel FT. Chronic benign cervical pain syndromes. Surgical considerations. Spine (Phila Pa 1976). 1992;17(10 Suppl):S367-S374.
25. Berven S, Tay BBK, Colman W, Hu SS. The lumbar zygapophyseal (facet) joints: a role in the pathogenesis of spinal pain syndromes and degenerative spondylolisthesis. Semin Neurol. 2002;22(2):187-196.

26. Yin W, Bogduk N. The nature of neck pain in a private pain clinic in the United States. Pain Med. 2008;9(2):196-203.

27. Henderson CM, Hennessy RG, Shuey HM, Shackelford EG. Posterior-lateral foraminotomy as an exclusive operative technique for cervical radiculopathy: a review of 846 consecutively operated cases. Neurosurgery. 1983;13(5):504-512.

28. Bogduk N, Windsor M, Inglis A. The innervation of the cervical intervertebral discs. Spine (Phila Pa 1976). 1988;13(1):2-8.

29. Lord SM, Barnsley L, Wallis BJ, Bogduk N. Chronic cervical zygapophysial joint pain after whiplash. A placebocontrolled prevalence study. Spine (Phila Pa 1976). 1996;21(15):1737-1744.

30. Speldewinde GC, Bashford GM, Davidson IR. Diagnostic cervical zygapophyseal joint blocks for chronic cervical pain. Med J Aust. 2001;174(4):174-176.

31. Chotai S, Sivaganesan A, Parker SL, McGirt MJ, Devin CJ. Patient-specific factors associated with dissatisfaction after elective surgery for degenerative spine diseases. Neurosurgery. 2015;77(2):157-163.

32. Persson LC, Carlsson C, Carlsson JY. Long-lasting cervical radicular pain managed with surgery, physiotherapy, or a cervical collar. A prospective, randomized study. Spine. 1997;22(7):751-758.

33. Petersen OF, Buhl M, Eriksen EF, et al. The significance of preoperative radiological examinations in patients treated with Cloward's operation. Acta Neurochir (Wien). 1987;88(12):39-45.

34. White AA, Southwick WO, Deponte RJ, Gainor JW, Hardy R. Relief of pain by anterior cervical-spine fusion for spondylosis. A report of sixty-five patients. J Bone Joint Surg Am. 1973;55(3):525-534.

35. Smith GW, Robinson RA. The treatment of certain cervical-spine disorders by anterior removal of the intervertebral disc and interbody fusion. J Bone Joint Surg Am. 1958;40A(3):607-624.

36. Eck JC, Humphreys SC, Hodges SD, Levi P. A comparison of outcomes of anterior cervical discectomy and fusion in patients with and without radicular symptoms. J Surg Orthop Adv. 2006;15(1):24-26.

37. Garvey TA, Transfeldt EE, Malcolm JR, Kos P. Outcome of anterior cervical discectomy and fusion as perceived by patients treated for dominant axial-mechanical cervical spine pain. Spine (Phila Pa 1976). 2002;27(17):18871895; discussion 1895.

38. MacDermid JC, Walton DM, Avery S, et al. Measurement properties of the neck disability index: a systematic review. J Orthop Sports Phys Ther. 2009;39(5):400-417.

39. Childs JD, Piva SR, Fritz JM. Responsiveness of the numeric pain rating scale in patients with low back pain. Spine (Phila Pa 1976). 2005;30(11):1331-1334.

40. Young IA, Cleland JA, Michener LA, Brown C. Reliability, construct validity, and responsiveness of the neck disability index, patient-specific functional scale, and numeric pain rating scale in patients with cervical radiculopathy. $\mathrm{Am} \mathrm{J}$ Phys Med Rehabil. 2010;89(10):831-839.

41. Carreon LY, Glassman SD, Campbell MJ, Anderson P. 
Neck Disability Index, short form-36 physical component summary, and pain scales for neck and arm pain: the minimum clinically important difference and substantial clinical benefit after cervical spine fusion. Spine J. 2010;10(6):469-474.

42. Parker SL, Godil SS, Shau DN, Mendenhall SK, McGirt MJ. Assessment of the minimum clinically important difference in pain, disability, and quality of life after anterior cervical discectomy and fusion: clinical article. J Neurosurg Spine. 2013;18(2):154-160.

43. Godil SS, Parker SL, Zuckerman SL, Mendenhall SK, McGirt MJ. Accurately measuring the quality and effectiveness of cervical spine surgery in registry efforts: determining the most valid and responsive instruments. Spine J. 2015;15(6):1203-1209.

44. Peolsson A, Hedlund R, Vavruch L, Oberg B. Predictive factors for the outcome of anterior cervical decompression and fusion. Eur Spine J. 2003;12(3):274-280.

45. Price DD, McGrath PA, Rafii A, Buckingham B. The validation of visual analogue scales as ratio scale measures for chronic and experimental pain. Pain. 1983;17(1):45-56.

Disclosures and COI: Dr. Passias reports consultancy for Medicrea and SpineWave, speak- ing/teaching arrangements from Zimmer-Biomet, and grant from CSRS, all outside the submitted work. All other authors have no conflicts of interest to report. Institutional Review Board (IRB) approval was obtained from each contributing center prior to study initiation.

Corresponding Author: Peter G. Passias, MD, New York Spine Institute, New York University Medical Center - Hospital for Joint Diseases, New York, New York 10003. Phone: (516) 3578777; Fax: (516) 357-0087; Email: peter.passias@ nyumc.org.

Published 15 October 2018

This manuscript is generously published free of charge by ISASS, the International Society for the Advancement of Spine Surgery. Copyright (C) 2018 ISASS. To see more or order reprints or permissions, see http://ijssurgery.com. 